Author Contributions: Drs Daniele and Seripa contributed equally to this study.

Financial Disclosure: None reported.

Funding/Support: This study was partially supported by grants No. AN/F9 and Istituti di Ricovero e Cura a Carattere Scientifico Research Program, Ricerca Corrente 2006-2008, Linea No. 2 "Malattie di rilevanza sociale" from the Italian Ministry of Health.

1. Acciarri A, Masullo C, Bizzarro A, et al. ApoE epsilon2-epsilon4 genotype is a possible risk factor for primary progressive aphasia. Ann Neurol. 2006;59 (2):436-437.

2. Mesulam MM. Primary progressive aphasia. Ann Neurol. 2001;49(4):425-432.

3. McKhann GM, Albert MS, Grossman M, Miller B, Dickson D, Trojanowski JQ; Work Group on Frontotemporal Dementia and Pick's Disease. Clinical and pathological diagnosis of frontotemporal dementia: report of the Work Group on Frontotemporal Dementia and Pick's Disease. Arch Neurol. 2001;58(11):1803-1809.

4. Srinivasan R, Davidson Y, Gibbons L, et al. The apolipoprotein E epsilon4 allele selectively increases the risk of frontotemporal lobar degeneration in males. J Neurol Neurosurg Psychiatry. 2006;77(2):154-158.

5. Mann DM, McDonagh AM, Pickering-Brown T, Kowa H, Iwatsubo T. Amyloid beta protein deposition in patients with frontotemporal lobar degeneration: relationship to age and apolipoprotein E genotype. Neurosci Lett. 2001; 304(3):161-164.

6. Comings DE, MacMurray JP. Molecular heterosis: a review. Mol Genet Metab. 2000;71(1-2):19-31

\section{COMMENTS AND OPINIONS}

\section{Mediferranean Dietary Pattern, Mild Cognitive Impairment, and Progression to Dementia}

S

carmeas et $\mathrm{al}^{1}$ reported the results of a very interesting community-based study, the Washington Heights-Inwood Columbia Aging Project involving 2364 nondemented individuals in New York, New York, in which adherence to a traditional Mediterranean $\operatorname{diet}(\mathrm{MeDi})$ was associated with a borderline reduction in the risk of developing mild cognitive impairment $(\mathrm{MCI})$ and a reduction in the risk of progression from $\mathrm{MCI}$ to Alzheimer disease (AD). In this sample, these associations did not attenuate even when simultaneously adjusting for many commonly considered potential confounders (age, sex, ethnicity, education, apolipoprotein E [APOE] genotype, caloric intake, and body mass index). Scarmeas and colleagues also found that an association between higher adherence to the MeDi and lower risk of conversion to $\mathrm{AD}$ was much more prominent for subjects who had MCI without memory impairment.

We greatly appreciated these and previous findings from the Washington Heights-Inwood Columbia Aging Project, in which higher adherence to the MeDi was associated with a significant reduction in risk of incident $\mathrm{AD}^{2}$ (without vascular mediation ${ }^{3}$ ) and with decreased $\mathrm{AD}$ mortality. ${ }^{4}$ In fact, the MeDi could be an interesting model to further study the association between dietary patterns and predementia syndromes given the suggested role of many components of this diet in contrasting cognitive impairment. ${ }^{5}$ Findings from the Italian Longitudinal Study on Aging ${ }^{6}$ demonstrated that in an 8.5-year follow-up, high levels of monounsaturated fatty acids, polyunsaturated fatty acids, and total energy intake were significantly associated with decreased agerelated cognitive decline. Furthermore, in the same sample ${ }^{7}$ high levels of polyunsaturated fatty acids intake appeared to have a borderline nonsignificant trend for a protective effect against the development of MCI. Finally, alcohol consumption was associated with a decrease in the rate of progression of MCI to dementia. ${ }^{8,9}$ The wide diffusion of the whole-diet approach used by Scarmeas and colleagues has undeniable advantages, but some concerns exist. ${ }^{10}$ In particular, as underlined for previous studies on the same sample, ${ }^{11,12}$ using such a score in an American population might not adequately represent conformity with the traditional MeDi. Another recent study on diet and mortality in the United States considered alternate cut points because of concern that the median intake of some dietary components might be lower in the US population than in a Mediterranean population. ${ }^{13}$ Furthermore, these authors correctly defined the diet of their US sample only as a Mediterranean dietary pattern and not as a properly defined MeDi. Using this approach in a sensitivity analysis, the authors assigned points to only the highest intakes, and the diets consumed were in this manner more compatible with the traditional MeDi.

Moreover, in the Washington Heights-Inwood Columbia Aging Project, the general MCI prevalence (23.9\%) and amnestic MCI prevalence (7.4\%) appeared to be abnormally larger with respect to most other population-based studies. ${ }^{14}$ In fact, population-based studies estimate the prevalence of MCI to be more than double that of dementia. However, the diagnostic criteria and referral patterns used vary between studies, causing discrepant prevalence estimates. ${ }^{14}$ In the Italian Longitudinal Study of Aging, we used a more general concept of MCI, selecting these patients with MCI on the basis of the memory loss. ${ }^{15}$ Prevalence estimates of general MCI in other worldwide population-based studies are consistent with those reported in the Italian Longitudinal Study of Aging $(3.2 \%)^{15}: 3 \%$ in France, $3.1 \%$ in Germany, 3.02\% in Canada, and 3.2\% in the United States (Monongahela Valley Independent Elders Survey study), with 1 notable exception. ${ }^{14}$ The Cardiovascular Health Study Cognition Study ${ }^{16}$ found an amnestic MCI prevalence of 6\% among 599 participants, whereas the overall prevalence of $\mathrm{MCI}$, including the MCI subtype of multiple cognitive domains slightly impaired, was 19\% among 2470 participants. Other populationbased studies reported higher prevalence rates (6.1\%$15 \%$ ) but with MCI constructs different from the amnestic variants. ${ }^{14}$ Therefore, it is possible that in the Washington Heights-Inwood Columbia Aging Project, a percentage of cognitively unimpaired subjects were diagnosed as having MCI. The 1.5-SD cutoff score used by Scarmeas and colleagues to define cognitive impairment is very conservative with respect to the criteria proposed by most other studies ( $<10 \%$ instead of about $15 \%$ ). Also, unadjusted punctual estimates for test for trend (hazard ratio, 0.85 for the risk of incident MCI for subjects who were cognitively normal at the first evaluation vs 0.82 for the risk of incident Alzheimer disease for subjects with $\mathrm{MCI}$ at the first evaluation) were very similar but with an interesting different influence of negative confounding in the 2 adjusted models. ${ }^{1}$ Finally, there was no difference in the percentage of APOE $\varepsilon 4$ allele carriers between subjects who were cognitively unimpaired and those with MCI. Other stud- 
ies found significant differences in $A P O E \varepsilon 4$ allele frequencies between cognitively unimpaired subjects and patients with $\mathrm{MCI},{ }^{17}$ further supporting that some cognitively unimpaired subjects could have been included in the MCI sample of the Washington Heights-Inwood Columbia Aging Project.

We agree with Scarmeas and colleagues that the lack of association between the MeDi score and incident $\mathrm{MCI}^{1}$ and between individual food components (eg, alcohol or polyunsaturated fatty acids) and incident $\mathrm{MCI}^{7,8}$ could be partly explained by these different definitions of the outcome. However, we should not renounce a priori the work for a correct estimate of the validity of the MeDi score for cognitive impairment as a criterion.

Vincenzo Solfrizzi, MD, PhD
Vincenza Frisardi, MD
Cristiano Capurso, MD, PhD
Alessia D'Introno, PhD
Anna M. Colacicco, PhD
Gianluigi Vendemiale, MD
Antonio Capurso, MD
Francesco Panza, MD, PhD

Correspondence: Dr Panza, Department of Geriatrics, Center for Aging Brain, Memory Unit, University of Bari, Policlinico, Piazza Giulio Cesare, 11, Bari 70124, Italy (geriat.dot@geriatria.uniba.it).

Financial Disclosure: None reported.

Funding/Support: This work was supported by grants 9400419PF40 and 95973PF40 from the Italian National Research Council, Targeted Project on Ageing, for the Italian Longitudinal Study on Aging (Drs Solfrizzi, D'Introno, Colacicco, A. Capurso, and Panza).

Role of the Sponsor: The funding agencies had no role in the design or conduct of the study.

1. Scarmeas N, Stern Y, Mayeux R, Manly JJ, Schupf N, Luchsinger JA. Mediterranean diet and mild cognitive impairment. Arch Neurol. 2009;66(2): 216-225.

2. Scarmeas N, Stern Y, Tang MX, Mayeux R, Luchsinger JA. Mediterranean diet and risk for Alzheimer's disease. Ann Neurol. 2006;59(6):912-921.

3. Scarmeas N, Stern Y, Mayeux R, Luchsinger JA. Mediterranean diet, Alzheimer disease, and vascular mediation. Arch Neurol. 2006;63(12):1709-1717.

4. Scarmeas N, Luchsinger JA, Mayeux R, Stern Y. Mediterranean diet and Alzheimer disease mortality. Neurology. 2007;69(11):1084-1093.

5. Solfrizzi V, Capurso C, D'Introno A, et al. Lifestyle-related factors in predementia and dementia syndromes. Expert Rev Neurother. 2008;8(1):133158.

6. Solfrizzi V, Colacicco AM, D'Introno A, et al. Dietary intake of unsaturated fatty acids and age-related cognitive decline: a 8.5-year follow-up of the Italian Longitudinal Study on Aging. Neurobiol Aging. 2006;27(11):1694-1704.

7. Solfrizzi V, Colacicco AM, D'Introno A, et al. Dietary fatty acids intakes and rate of mild cognitive impairment: the Italian Longitudinal Study on Aging. Exp Gerontol. 2006;41(6):619-627.

8. Solfrizzi V, D'Introno A, Colacicco AM, et al; Italian Longitudinal Study on Aging Working Group. Alcohol consumption, mild cognitive impairment, and progression to dementia. Neurology. 2007;68(21):1790-1799.

9. Panza F, Capurso C, D'Introno A, et al. Alcohol drinking, cognitive functions in older age, predementia, and dementia syndromes. J Alzheimers Dis. $2009 ; 17(1)$. In press.

10. Solfrizzi V, Capurso C, D'Introno A, Colacicco AM, Capurso A, Panza F. Whole-diet approach and risk of chronic disease: limits and advantages. J Am Geriatr Soc. 2006;54(11):1800-1802.

11. Solfrizzi V, Capurso C, Panza F. Adherence to a Mediterranean dietary pattern and risk of Alzheimer's disease. Ann Neurol. 2006;60(5):620.

12. Solfrizzi V, Capurso C, D'Introno A, et al. Whole-diet approach, Mediterranean diet, and Alzheimer disease. Arch Neurol. 2007;64(4):606.

13. Mitrou PN, Kipnis V, Thiébaut AC, et al. Mediterranean dietary pattern and prediction of all-cause mortality in a US population: results from the NIHAARP Diet and Health Study. Arch Intern Med. 2007;167(22):2461-2468.

14. Panza F, D'Introno A, Colacicco AM, et al. Current epidemiology of mild cognitive impairment and other predementia syndromes. Am J Geriat Psychiatry. 2005;13(8):633-644.

15. Solfrizzi V, Panza F, Colacicco AM, et al; Italian Longitudinal Study on Aging Working Group. Vascular risk factors, incidence of $\mathrm{MCI}$, and rates of progression to dementia. Neurology. 2004;63(10):1882-1891.

16. Lopez OL, Jagust WJ, DeKosky ST, et al. Prevalence and classification of mild cognitive impairment in the Cardiovascular Health Study Cognition Study: part 1. Arch Neurol. 2003;60(10):1385-1389.

17. Orsitto G, Seripa D, Panza F, et al. Apolipoprotein E genotypes in mild cognitive impairment subtypes. J Am Geriatr Soc. 2006;54(12):1965-1966.

\section{In reply}

In their letter, Solfrizzi and colleagues raise concerns similar to those they have previously expressed in response to our work on this topic. They suggest the possible use of the alternate cut point method applied by Mitrou et al (ie, rather than using the 50th percentile, assigning points to intakes $\geq 25$ th percentile or $<75$ th percentile for "beneficial" or "detrimental" components of the MeDi calculation) for a sensitivity analysis. Unfortunately, using this method is not practical in our study owing to power limitations. More specifically, in applying this method in the cognitively normal to incident MCI analyses (N=1393), a MeDi score of 6 would be assigned to 23 subjects $(1.7 \%)$, a score of 7 to 9 subjects $(0.6 \%)$, a score of 8 to 1 subject (0.1\%), and a score of 9 to 0 subjects. Overall, only 33 of 1393 subjects (2.4\%) would obtain a MeDi score greater than 5. In adjusted analyses, the risk of incident MCI for those 33 subjects was 0.38 (95\% confidence interval, 0.12-1.19; $\mathrm{P}=.09)$. In applying this alternate cutoff method in the MCI to incident $A D$ analyses $(N=482), a \mathrm{MeDi}$ score of 6 would be assigned to 6 subjects (1.2\%), a score of 7 to 1 subject (0.2\%), and a score of 8 or 9 to 0 subjects. Overall, only 7 of 482 subjects with MCI (1.5\%) would obtain a $\mathrm{MeDi}$ score greater than 5. In adjusted analyses, the risk of incident $A D$ for those 7 subjects was 0.23 (95\% confidence interval, 0.03-1.71; $\mathrm{P}=.15$ ). Summarizing, in both the incident MCI and incident $A D$ analyses, the effect sizes (as judged by the coefficient magnitudes) are clearly quite strong, but owing to obvious power limitations the confidence intervals are wide, precluding statistical significance. To put things in perspective, Mitrou and colleagues were able to apply the alternate MeDi score calculation method because of the luxury of including in the study 214284 men and 166012 women from the American Association of Retired Persons database. Overall, our study was conducted in a multiethnic urban cohort from New York, New York, and these individuals are unlikely to strictly consume the foods typical of Mediterranean countries. A "true" MeDi may have even more beneficial effects in cognition, but this does not invalidate our MeDi score calculations and certainly does not negate the benefit of a diet closer to the Mediterranean type in our cohort.

In another line of comments, Solfrizzi and colleagues state that general MCI and amnestic MCI prevalences in our cohort are $23.9 \%$ and $7.4 \%$, respectively. The actual published numbers are $28.3 \%$ and $5.0 \% .{ }^{2}$ Irrespective of the exact magnitude of these numbers, there is clear variability in reported MCI frequencies in the literature, with studies reporting either low or high frequencies. ${ }^{3-5}$ This may result from variability in MCI definition, population differences, etc. Regarding MCI diagnosis, Solfrizzi and colleagues speculate that cognitively unimpaired subjects may have been diagnosed with MCI in our cohort, while admitting in the next sentence that we have used a very conservative cutoff of ap- 
proximately $7 \%$ (1.5 SD), which one would expect to lead to an underestimation of MCI frequencies. We would also add to this that the 1.5-SD cutoffs have been estimated using normative corrections for age, education, ethnicity, and sex. ${ }^{2,6}$ Similarly, the absence of APOE genotype differences between cognitively normal and MCI groups does not necessarily support the notion of misdiagnosing cognitively unimpaired subjects as having MCI. There is uncertainty on the topic in the literature ${ }^{7,8}$; various factors, including differential APOE genotype effects for different ethnicities, ${ }^{9}$ may play a role, particularly in our cohort. Overall, we believe that our diagnostic procedures minimize the possibility of misattributing MCI diagnoses to cognitively normal subjects. Whether all subjects with MCI harbor underlying neurodegenerative pathological changes is a different question, and we believe that this is clearly not the case given the often noted lack of conversion to dementia in populationbased studies. ${ }^{6,10}$ In view of this, it is possible that an MCI diagnosis enriched with subjects who are cognitively impaired because of nondegenerative causes may have contributed to a relatively weaker protective effect of the $\mathrm{MeDi}$ regarding MCI incidence. ${ }^{11}$

\section{Nikolaos Scarmeas, MD Yaakov Stern, PhD Jennifer J. Manly, PhD Nicole Schupf, PhD Jose A. Luchsinger, MD Richard Mayeux, MD}

Correspondence: Dr Scarmeas, Columbia University Medical Center, 622 W 168th St, PH 19th Floor, New York, NY 10032 (ns257@columbia.edu).

Financial Disclosure: None reported.

Funding/Support: This work was supported by grants AG028506, P01-AG07232, and RR00645 from the National Institute on Aging.

1. Mitrou PN, Kipnis V, Thiebaut AC, et al. Mediterranean dietary pattern and prediction of all-cause mortality in a US population: results from the NIHAARP Diet and Health Study. Arch Intern Med. 2007;167(22):2461-2468.

2. Manly JJ, Bell-McGinty S, Tang MX, Schupf N, Stern Y, Mayeux R. Implementing diagnostic criteria and estimating frequency of mild cognitive impairment in an urban community. Arch Neurol. 2005;62(11):1739-1746.

3. Geda YE, Roberts RO, Knopman DS, et al. Prevalence of neuropsychiatric symptoms in mild cognitive impairment and normal cognitive aging: population-based study. Arch Gen Psychiatry. 2008;65(10):1193-1198.

4. Roberts RO, Geda YE, Knopman DS, et al. The Mayo Clinic Study of Aging: design and sampling, participation, baseline measures and sample characteristics. Neuroepidemiology. 2008;30(1):58-69.

5. Lopez OL, Jagust WJ, DeKosky ST, et al. Prevalence and classification of mild cognitive impairment in the Cardiovascular Health Study Cognition Study: part 1. Arch Neurol. 2003;60(10):1385-1389.

6. Manly JJ, Tang MX, Schupf N, Stern Y, Vonsattel JP, Mayeux R. Frequency and course of mild cognitive impairment in a multiethnic community. Ann Neurol. 2008;63(4):494-506.

7. Tierney MC, Szalai JP, Snow WG, et al. A prospective study of the clinical utility of ApoE genotype in the prediction of outcome in patients with memory impairment. Neurology. 1996;46(1):149-154

8. Devanand DP, Pelton GH, Zamora D, et al. Predictive utility of apolipoprotein E genotype for Alzheimer disease in outpatients with mild cognitive impairment. Arch Neurol. 2005:62(6):975-980.

9. Tang MX, Stern Y, Marder K, et al. The APOE-epsilon4 allele and the risk of Alzheimer disease among African Americans, whites, and Hispanics. JAMA. 1998;279(10):751-755.

10. Larrieu S, Letenneur L, Orgogozo JM, et al. Incidence and outcome of mild cognitive impairment in a population-based prospective cohort. Neurology. 2002;59(10):1594-1599.

11. Scarmeas N, Stern Y, Mayeux R, Manly JJ, Schupf N, Luchsinger JA. Mediterranean diet and mild cognitive impairment. Arch Neurol. 2009;66(2): 216-225.

\section{Parkinson Disease: Extranigral, Multisystem, and $\alpha$-Synuclein "Plus"}

$T$ he review by Lim et al ${ }^{1}$ reminds its audience that Parkinson disease (PD) is a multisystem disorder. While the review addresses the multiplicity of derangements in the PD brain with resultant clinical manifestations and also alludes to pathologic findings other than $\alpha$-synuclein deposition, certain further facts need to be mentioned in the context of "extranigral" pathologic findings.

Lim and colleagues state that "the Braak staging scheme. . . has been largely confirmed by other investigators ... " and thereby cite an article by Dickson et al. ${ }^{2}$ In fact, the study by Dickson and colleagues did not seek explicitly to address the staging of $\alpha$-synuclein deposition. Rather, it demonstrated that in incidental Lewy body disease cases, $\alpha$-synuclein pathologic findings were observed simultaneously in multiple regions of both the central and peripheral nervous systems, implying "a multicentric process from its earliest stages" and thus contradicting a predictable caudorostral progression of $\alpha$ synuclein pathologic findings. While failing to support the Braak hypothetical staging of $\alpha$-synuclein pathologic findings, the incidental Lewy body disease cases identified by Dickson and colleagues also had a mean Braak PD stage of 3; it was therefore unsurprising that there was robust correlation with markers of neuronal loss and dysfunction as compared with control subjects and patients with PD.

Lim and colleagues acknowledge criticisms with respect to the Braak PD staging system that echo our own observations. ${ }^{3}$ Indeed, as the presence of $\alpha$-synuclein may reflect protective or compensatory mechanisms, staging PD in this way may not reflect the integrity of neuronal number and function. ${ }^{3-6}$ Of greatest concern is that Braak and colleagues ${ }^{7,8}$ derived asymptomatic stages of $\alpha$-synuclein pathologic findings by generating a spurious "earliest-stage" sample of medulla-positive cases through exercising a selection bias. ${ }^{3,5,6,9}$ Several groups, including Dickson and colleagues, ${ }^{2}$ have reported that $\alpha$-synuclein inclusions are present rostrally while absent from medullary and more caudal nuclei, ${ }^{9-12}$ with evidence also existing for spinal cord involvement without vagal pathologic findings. ${ }^{3,9}$

Furthermore, at Braak stages 5 and 6, there is the major problem that a substantial proportion of cases will have no overt cognitive or motor impairment. ${ }^{4}$ Lim and colleagues admit this disjunction between severe $\alpha$-synuclein pathologic findings and absent clinical signs as well as the difficulty arising in defining the pathologic substrate for PD dementia (PDD). While they state that PDD does not relate to comorbid classic Alzheimer disease pathologic findings, we have described a robust correlation of PDD with striatal $\beta$-amyloid deposition, ${ }^{13}$ yet a further reminder that adherence to a fashionable staging system for $\alpha$-synuclein deposition arising from preselected cases for its earliest footprints and lacking reliable clinicopathologic correlation in its gravest extent risks repeating the error of simplification in viewing PD merely as a dopamine deficiency syndrome. These points aside, 